\title{
PENGARUH PROMOSI TERHADAP PENJUALAN PAKET WISATA (Studi Kasus : Biro Perjalanan Wisata Pasir Putih Adventure Di Sabang)
}

\author{
The Effect of Promotion on Tour Package Sale \\ (A Case Study on Pasir Putih Adventure Travel Bureau In Sabang)
}

\author{
Zahra F. Maiyuriyda, Sofyan ${ }^{1}$, Irwan A Kadir ${ }^{*}$ \\ ${ }^{1}$ Program Studi Agribisnis, Fakultas Pertanian, Universitas Syiah Kuala
}

\begin{abstract}
Abstrak. Biro perjalanan wisata merupakan salah satu usaha pariwisata yang sangat mendukung perkembangan pariwisata. Sama seperti usaha lainnya yang memiliki tujuan untuk mendapatkan keuntungan yang besar sebagai tolak ukur dari kesuksesan usahanya, biro perjalanan wisata juga harus berhasil menjual paket wisata sebagai produk usahanya dalam jumlah yang tinggi. Untuk tercapainya tujuan ini maka biro perjalanan wisata harus melakukan berbagai kegiatan promosi dan mengeluarkan sejumlah biaya untuk melakukan kegiatan tersebut. Pasir Putih Adventure adalah salah satu biro perjalanan wisata di Sabang yang aktif dalam melakukan promosi usahanya baik di tingkat nasional maupun internasional. Metode yang digunakan dalam analisis ini adalah analisis regresi linier sederhana, analisis koefisien korelasi, koefisien determinasi dan uji-t. Analisis linier regresi sederhana menunjukkan bahwa $\mathrm{Y}=28,401+0,015 \mathrm{X}$ (jika biaya promosi sama dengan nol maka penjualan paket wisata meningkat sebesar 28,401), nilai koefisien korelasi sebesar 0,662 (hubungan antar kedua variabel kuat), koefisien determinasi sebesar 0,439 dan nilai uji-t adalah $\mathrm{t}_{\text {hitung }}>\mathrm{t}_{\text {tabel }}=4,147>1,717$, artinya promosi pada biro perjalanan wisata Pasir Putih Adventure berpengaruh secara positif terhadap jumlah penjualan paket wisata.
\end{abstract}

Kata kunci: Promosi, Penjualan, Paket Wisata.

\begin{abstract}
Travel bureau is one of the tourism businesses that strongly supports the development of tourism. Just like any other business that has the goal of gaining big profits as a benchmark for its business success, travel agency must also succeed in selling tour packages as a product of their business in high numbers. To achieve this goal, the travel bureau must carry out various promotional activities and spend a number of costs to carry out these activities. Pasir Putih Adventure is one of the travel bureau in Sabang that active in promoting its business both nationally and internationally. The methods used in this analysis is simple linear regression analysis, correlation coefficient analysis, coefficient of determination and t-test. Simple linear regression analysis shows that $\mathrm{Y}=28,401+0,015 \mathrm{X}$ (if the promotion costs equal to zero then the tour package sales increase by 28,401 ), the correlation coefficient value is 0,662 (the relationship between the two strong variables), the coefficient of determination is 0,439 and the $t$-test value is $t_{\text {search }}>t_{\text {table }}=4,147>1,717$ meaning that the promotion of the Pasir Putih Adventure travel bureau has a positive effect on the number of the tour package sale.
\end{abstract}

Keywords: Promotion, Sale, Tour Package.

\section{PENDAHULUAN}

Pariwisata merupakan salah satu sektor penyumbang devisa terbesar bagi Indonesia. Dari posisi penyumbang devisa terbesar keempat di tahun 2015 dengan devisa sebesar US\$ 12,2 juta, pariwisata terus mengalami peningkatan devisa menjadi US $\$ 13,6$ juta pada tahun 2016 dan US\$ 16,8 juta pada tahun 2017, sehingga pariwisata dijadikan salah satu dari lima sektor pembangunan nasional. Pariwisata juga dapat dengan cepat mengurangi tingkat kemiskinan karena terbukanya peluang bagi masyarakat lokal di daerah wisata untuk membuka usaha, memasarkan produk, pelayanan dan jasa bagi wisatawan. Sabang sebagai kota yang terletak di pulau kecil di ujung barat Indonesia memiliki keindahan wisata bahari yang menjadi salah satu destinasi wisata pilihan bagi wisatawan. Salah satu daya tarik wisata bahari yang paling utama di Sabang adalah taman wisata bawah laut yang terletak di antara 
kawasan pesisir pantai Iboih dan Pulau Rubiah yang memiliki keanekaragaman hayati yang tinggi mulai dari berbagai jenis karang, ikan dan biota bawah laut yang antara lain adalah Nautilus pomplitus, Turbo marmoratus, Trochus nilatimus, Cassis comuta, Bircus latro, Charonia Trittonis, Anthiphates sp, yang dapat dilihat dengan jelas karena kondisi air laut yang tenang dan jernih sehingga dapat dinikmati langsung oleh wisatawan dengan cara menyelam (diving), snorkling, ataupun hanya dengan menggunakan perahu kaca yaitu katamaran yang telah dilengkapi dengan kotak kaca untuk melihat pemandangan bawah laut tersebut.

Kemudahan akses transportasi melalui udara dan laut pun menjadi salah satu faktor peningkatan jumlah kunjungan wisatawan pada setiap tahunnya, baik itu wisatawan domestik maupun mancanegara. Pada tahun 2017, jumlah wisatawan yang berkunjung ke Sabang mencapai 742.306 orang yang terdiri dari 6.031 orang wisatawan mancanegara dan 736.275 orang wisatawan domestik. Daya tarik wisata bahari di Sabang tidak hanya bisa dinikmati dengan melihat taman bawah lautnya tetapi juga dapat dinikmati dengan mengkonsumsi produk perikanannya.

Perkembangan pariwisata tentunya tidak terlepas dari dukungan berbagai aspek penunjang yang sangat penting seperti penginapan, rumah makan, transportasi, hiburan, pusat belanja oleh-oleh dan biro perjalanan wisata. Dari segi kontribusinya, biro perjalanan wisata dapat memberikan lebih dari satu kontribusi kepada negara yaitu, dari pajak yang dibayarkan oleh biro perjalanan wisata, penerimaan devisa dari wisatawan asing, dan mendorong perkembangan usaha pariwisata lainnya sebagai akibat dari banyaknya jumlah wisatawan yang dibawa oleh biro perjalanan wisata.

Di era kemudahan akses informasi, persaingan dalam berbagai jenis usaha semakin ketat begitu pula pada biro perjalanan wisata. Salah satu upaya yang dilakukan oleh biro perjalanan wisata agar mampu bersaing dalam pemasaran adalah dengan melakukan promosi untuk meningkatkan penjualan produk usahanya yaitu paket wisata. Pasir Putih Adventure adalah salah satu biro perjalanan wisata di Sabang yang aktif dalam melakukan promosi usahanya baik di tingkat nasional maupun internasional. Tetapi sampai saat ini belum ada informasi yang mengungkapkan apakah promosi yang dilakukan mampu meningkatkan jumlah penjualan paket wisata di Sabang. Oleh sebab itu perlu dilakukan penelitian tentang pengaruh promosi terhadap penjualan paket wisata Penelitian ini bertujuan untuk mengetahui pengaruh yang terjadi pada penjualan paket wisata setelah dilakukannya promosi oleh Biro Perjalanan Wisata Pasir Putih Adventure di Sabang.

\section{METODE PENELITIAN}

\section{Lokasi dan Waktu Penelitian}

Penelitian ini dilaksanakan di Kota Sabang. Penetuan lokasi penelitian ditentukan secara sengaja dengan pertimbangan Sabang merupakan salah satu daerah yang sedang berkembang sektor wisatanya. Adapun waktu penelitian berlangsung dari bulan Mei 2018 hingga selesai.

\section{Objek dan Ruang Lingkup Penelitian}

Objek penelitian adalah usaha biro perjalanan wisata Pasir Putih Adventure yang terletak di Sabang. Ruang lingkup penelitian ini adalah kegiatan promosi yang pernah dilakukan oleh Pasir Putih Adventure, biaya promosi yang telah dikeluarkan, serta jumlah penjualan paket wisata selama kurun waktu dua tahun. 


\section{Sumber dan Metode Pengumpulan Data}

Metode yang digunakan dalam penelitian ini adalah Metode Wawancara, dimana pemilik usaha dijadikan sebagai narasumber data penelitian.

\section{Metode Analisis}

\section{A. Analisis Regresi Linier Sederhana}

$$
\mathrm{Y}=\mathrm{a}+\mathrm{bX}
$$

..(Sujarweni et al, 2012)

Keterangan:

Y : jumlah penjualan paket wisata (pax)

a : konstan

b : biaya promosi (Rp)

$\mathrm{X}$ : variabel bebas

\section{B. Analisis Koefisien Korelasi (R)}

$$
R=\frac{n \sum x y-\left(\sum x\right)\left(\sum y\right)}{\sqrt{\left\{\left(n \sum x^{2}\right)-\left(\sum x\right)^{2}\right\}\left\{\left(n \sum y^{2}\right)-\left(\sum y\right)^{2}\right\}}} .
$$

Keterangan:

R : koefisien korelasi

$\mathrm{n} \quad$ : jumlah data

$\sum \mathrm{x} \quad$ : jumlah nilai variabel bebas $\mathrm{x}$ (biaya promosi)

$\sum y \quad$ : jumlah nilai variabel terikat y (jumlah paket wisata terjual)

\section{Koefisien Determinasi $\left(\mathbf{R}^{2}\right)$}

$$
\mathrm{R}^{2}=\frac{j k_{(r e g)}}{\sum y i^{2}} \ldots \ldots . .(\text { Sudjana, 2002) }
$$

Keterangan:

$j k_{(r e g)}:$ Jumlah Kuadrat Regresi

$\sum y i^{2} \quad$ Jumlah Kuadrat Total

\section{Uji-t}

$$
t_{\text {Cari }}=\frac{\left|a_{i}\right|}{S E_{a i}} \ldots \ldots . .(\text { Sudjana, 2002) }
$$

$a_{i} \quad$ : Koefisien Regresi yang ke-i

$\mathrm{SE}_{\mathrm{ai}} \quad$ : Standar Error ke-i

Hipotesis :

$\mathrm{H}_{0}$ : Promosi tidak berpengaruh secara positif terhadap jumlah penjualan paket wisata.

$\mathrm{H}_{\mathrm{a}}$ : Promosi berpengaruh secara positif terhadap jumlah penjualan paket wisata. 
Kriteria keputusan:

$t_{\text {hitung }}>t_{\text {tabel }}:$ Terima $\mathrm{H}_{\mathrm{a}}$ dan tolak $\mathrm{H}_{\mathrm{o}}$, artinya variabel bebas berpengaruh positif terhadap variabel terikat.

$\mathrm{t}_{\text {hitung }}<\mathrm{t}_{\text {tabel }}$ : Terima $\mathrm{H}_{\mathrm{o}}$ dan tolak $\mathrm{H}_{\mathrm{a}}$, artinya variabel bebas tidak berpengaruh positif terhadap variabel terikat.

\section{HASIL DAN PEMBAHASAN}

Dari hasil penelitian yang telah dilakukan, biro perjalanan wisata Pasir Putih Adventure diketahui aktif melakukan berbagai kegiatan promosi, yaitu melalui media sosial, brosur, dan iklan. Pasir Putih Adventure juga rutin mengikuti kegiatan pameran baik di dalam maupun luar negeri, diantaranya MATTA Fair di Malaysia, Deep Extreme di Jakarta dan Sales Mission di Malaysia. Adapun jumlah biaya yang dikeluarkan selama melakukan kegiatan promosi serta jumlah paket wisata yang berhasil terjual oleh Pasir Putih Adventure dapat dilihat pada tabel berikut :

Tabel 1. Biaya Promosi Pasir Putih Adventure Tahun 2016-2017

\begin{tabular}{lrr}
\hline & \multirow{2}{*}{ Bulan } & \multicolumn{2}{c}{ Biaya Promosi (Rp) } \\
\cline { 2 - 4 } & $\mathbf{2 0 1 6}$ & $\mathbf{2 0 1 7}$ \\
\hline Januari & 500.000 & 5.500 .000 \\
Februari & 3.500 .000 & 2.500 .000 \\
Maret & 5.500 .000 & 1.500 .000 \\
April & 3.000 .000 & 6.500 .000 \\
Mei & 2.000 .000 & 3.500 .000 \\
Juni & 1.500 .000 & 3.500 .000 \\
Juli & 3.500 .000 & 5.500 .000 \\
Agustus & 2.500 .000 & 4.500 .000 \\
September & 15.000 .000 & 8.500 .000 \\
Oktober & 8.000 .000 & 8.700 .000 \\
November & 7.500 .000 & 9.000 .000 \\
Desember & 8.000 .000 & 9.500 .000 \\
\hline Total Biaya Promosi & $\mathbf{6 0 . 5 0 0 . 0 0 0}$ & $\mathbf{6 8 . 7 0 0 . 0 0 0}$ \\
\hline Rata-Rata Biaya Promosi & $\mathbf{5 . 0 4 1 . 6 6 7}$ & $\mathbf{5 . 7 2 5 . 0 0 0}$ \\
\hline Sumber $:$ Pasir Putih Adverture $(d a t a d i a n)$
\end{tabular}

Sumber :Pasir Putih Adventure (data diolah)

Tabel 2. Penjualan Paket Wisata Pasir Putih Adventure Tahun 2016-2017

\begin{tabular}{lcr}
\hline & \multirow{2}{*}{ Bulan } & Penjualan Paket Wisata (Pax) \\
\cline { 2 - 3 } & $\mathbf{2 0 1 6}$ & $\mathbf{2 0 1 7}$ \\
\hline Januari & 51 & 32 \\
Februari & 25 & 40 \\
Maret & 23 & 25 \\
April & 57 & 151 \\
Mei & 51 & 71 \\
Juni & 55 & 52 \\
Juli & 83 & 170 \\
Agustus & 74 & 86 \\
September & 101 & 203 \\
Oktober & 155 & 161 \\
November & 209 & 200 \\
Desember & 253 & 254 \\
\hline Total Penjualan & $\mathbf{1 . 1 3 7}$ & $\mathbf{1 . 4 4 5}$ \\
\hline Rata-Rata Penjualan & $\mathbf{9 4 , 7 5}$ & $\mathbf{1 2 0 , 4 2}$ \\
\hline Sumber :Pasir Putih Adventure (data diolah) & &
\end{tabular}




\section{Analisis Regresi Linier Sederhana}

Data dari tabel diatas kemudian dianalisis menggunakan program SPSS17 yang hasilnya adalah sebagai berikut :

Tabel 3. Koefisien Regresi Linier Sederhana Antara Biaya Promosi Dengan Penjualan Paket Wisata

\begin{tabular}{clrr}
\hline No. & \multicolumn{1}{c}{ Koefisien Regresi } & t $_{\text {hitung }}$ \\
\hline 1 & Constant & 28,401 & 1,266 \\
2 & Biaya Promosi & 0,015 & 4,147 \\
\hline & Koefisien Korelasi & 0,662 & \\
& Koefisien Determinasi $\left(\mathrm{R}^{2}\right)$ & 0,439 & \\
& $\mathrm{t}_{\text {tabel }}$ & 1,717 & \\
\hline
\end{tabular}

Sumber : Output SPSS17 (diolah)

Dari Tabel 3 maka dapat ditulis persamaan regresi linier sederhana sebagai berikut :

$$
\mathrm{Y}=28,401+0,015 \mathrm{X}
$$

Berdasarkan persamaan di atas, nilai koefisien konstanta adalah 28,401 yang artinya jika biaya promosi sama dengan nol, maka jumlah penjualan paket wisata adalah 28,401 satuan. Nilai koefisien regresi pada biaya promosi adalah 0,015 yang artinya apabila biaya promosi naik 1 satuan maka akan menaikkan penjualan paket wisata sebesar 0,015 satuan.

\section{Analisis Koefisien Korelasi (R)}

Dari hasil perhitungan pada Tabel 3 diatas, diperoleh nilai korelasi sebesar 0,662. Nilai korelasi 0,662 berada di antara interval nilai 0,600-0,799 yang menunjukkan hubungan yang tinggi atau kuat. Jadi dapatlah diketahui bahwa biaya promosi memiliki hubungan yang kuat dengan penjualan paket wisata pada biro perjalanan wisata Pasir Putih Adventure.

\section{Koefisien Determinasi $\left(\mathbf{R}^{2}\right)$}

Dari hasil perhitungan pada Tabel 3 dapat diketahui bahwa nilai koefisien determinasi $\left(\mathrm{R}^{2}\right)$ adalah 0,439 . Hal ini menunjukkan bahwa biaya promosi berpengaruh sebesar $43,9 \%$ terhadap peningkatan penjualan paket wisata pada biro perjalanan wisata Pasir Putih Adventure, sedangkan sisanya yaitu sebesar 56,1\% dipengaruhi oleh variabel-variabel lain yang berada diluar penelitian ini.

\section{Uji-t}

Uji-t digunakan untuk mengetahui pengaruh variabel bebas terhadap variabel terikat. Untuk penarikan kesimpulan dilakukan dengan membandingkan antara $t_{c a r i}$ dengan $t_{\text {tabel }}$, dengan kriteria sebagai berikut :

$\mathrm{t}_{\text {hitung }}>\mathrm{t}_{\text {tabel}}$, maka $\mathrm{H}_{0}$ ditolak dan $\mathrm{H}_{\mathrm{a}}$ diterima

$\mathrm{t}_{\text {hitung }}<\mathrm{t}_{\text {tabel }}$, maka $\mathrm{H}_{0}$ diterima dan $\mathrm{H}_{\mathrm{a}}$ ditolak

Dengan tingkat signifikansi $5 \%(\alpha=0,05)$ dan derajat kebebasan $(\mathrm{df}=\mathrm{n}-2)$, diperoleh nilai $t_{\text {tabel }}$ sebesar 1,717. Berdasarkan hasil perhitungan pada Tabel 3 diketahui bahwa nilai $t_{\text {hitung }}$ adalah 4,147 maka dapat ditarik kesimpulan bahwa 4,147 > 1,717 yang berarti $t_{\text {hitung }}>$ $t_{\text {tabel. }}$. Dengan demikian maka $\mathrm{H}_{0}$ diterima dan $\mathrm{H}_{\mathrm{a}}$ ditolak, yang artinya bahwa promosi pada biro perjalanan wisata Pasir Putih Adventure berpengaruh secara positif terhadap jumlah penjualan paket wisata. 


\section{Simpulan}

\section{SIMPULAN DAN SARAN}

Promosi pada usaha biro perjalanan wisata Pasir Putih Adventure, berpengaruh positif terhadap jumlah penjualan paket wisata pada usaha biro perjalanan wisata Pasir Putih Adventure.

\section{Saran}

Berikut beberapa masukan yang dapat mejadi pertimbangan guna perbaikan dimasa mendatang : a) agar perusahaan biro perjalanan wisata Pasir Putih Adventure dapat memperbanyak jenis promosi yang dilakukan guna meningkatkan penjualan, b) agar perusahaan biro perjalanan wisata Pasir Putih Adventure dapat menambah jumlah karyawannya terutama pada bidang promosi sehingga kegiatan promosi bisa secara fokus ditangani oleh karyawan di bidang tersebut.

\section{DAFTAR PUSTAKA}

Damardjati, R.S. 2010. Manajemen Perjalanan Wisata. Penerbit Elex Media Komputindo. Jakarta

Dewi, M.N. dan H. Samuel. 2015. Pengaruh Gaya Hidup (Lifestyle), Harga, Promosi terhadap Pemilihan Tempat Tujuan Wisata Studi Kasus Pada Konsumen Artojaya Tour dan Travel Surabaya. Jurnal Manajemen Pemasaran Petra Volume 3 Nomor 1 (2015) 1-13. Universitas Kristen Petra. Surabaya.

Fiatiano, E. 2004. Perencanaan Paket Wisata atau Tur. Jurnal Masyarakat, Kebudayaan dan Politik Volume 22 Nomor 2, April 2009. Universitas Airlangga. Surabaya.

Firmansyah, F. 2014. Pengaruh Biaya Promosi dan Nisbah Bagi Hasil Terhadap Perkembangan Dana Pihak Ketiga dalam Bentuk Tabungan pada Bank Muamalat Indonesia. Skripsi. Universitas Islam Negeri Sultan Syarif Kasim. Riau.

Idaman, P. 2016. Usaha-Usaha Meningkatkan Volume Penjualan Pada Usaha Bakso dan Mie Ayam Mulyono Palembang. Skripsi. Politeknik Negeri Sriwijaya. Palembang.

Lahilote, H.S. 2010 Kajian Yuridis Terhadap Agen Perjalanan (Travel Agent) Dalam Bisnis Pariwisata. Jurnal Al Syir'ah Volume 8 Nomor 2, Desember 2010. Institut Agama Islam Negeri Manado. Manado.

Karim, D., J.L. Sepang, B. Lumanauw. 2014. Marketing Mix Pengaruhnya Terhadap Volume Penjualan Pada PT Manado Sejati Perkasa Group. Jurnal EMBA Volume 2 Nomor 1, Maret 2014. Universitas Sam Ratulangi. Manado.

Kementerian Pariwisata dan Ekonomi Kreatif. 2014. Peraturan Menteri Pariwisata dan Ekonomi Kreatif Nomor 4 Tahun 2014 tentang Standar Usaha Jasa Perjalanan Wisata. Republik Indonesia.

Makmur dan Safrijal. 2015. Strategi Pemasaran Dalam Meningkatkan Volume Penjualan. Jurnal Ilmiah Cano Ekonomos Volume 3 Nomor 1, Januari 2015. Universitas Pasir Pengaraian. Riau.

Pratama, A. 2017. Strategi Pemasaran Bisnis Travel Dalam Meningkatkan Jumlah Konsumen. Jurnal Ilmu dan Riset Manajemen Volume 6 Nomor 7, Juli 2017. Sekolah Tinggi Ilmu Ekonomi Indonesia. Surabaya.

Rangkuti, F. 2013. Strategi Promosi yang Kreatif dan Analisis Kasus Integrated Marketing Communication. PT Gramedia Pustaka Utama. Jakarta.

Sudjana. 2002. Metode Statistika. Tarsito. Bandung. 
Sujarweni, W. dan P. Endrayanto. 2012. Statistika Untuk Penelitian. Graha Ilmu. Yogyakarta.

Widiyanto, M.A. 2013. Statistika Terapan. Penerbit Elex Media Komputindo. Jakarta.

Wisnubroto, P. dan J.M. Freitas. 2013. Strategi Pemasaran Guna Meningkatkan Volume Penjualan dengan Pendekatan Technology Atlas Project Method. Jurnal Teknologi Volume 6 Nomor 2, Desember 2013. Institut Sains dan Teknologi AKPRIND. Yogyakarta. 